\title{
Confusing a Pollen Grain with a Parasite Egg: an Appraisal of "Paleoparasitological Evidence of Pinworm (Enterobius Vermicularis) Infection in a Female Adolescent Residing in Ancient Tehran"
}

\author{
Morgana Camacho ${ }^{1, *}$, Karl J. Reinhard ${ }^{2}$ \\ ${ }^{1}$ Escola Nacional de Saúde Pública Sergio Arouca, Fundação Oswaldo Cruz, Rio de Janeiro, Brazil; '2School of Natural Resource Sciences, \\ University of Nebraska, Lincoln, USA
}

\begin{abstract}
There is often the risk of confusing pollen grains with helminth eggs from archaeological sites. Thousands to millions of pollen grains can be recovered from archaeological burial sediments that represent past ritual, medication and environment. Some pollen grain types can be similar to parasite eggs. Such a confusion is represented by the diagnosis of enterobiasis in ancient Iran. The authors of this study confused a joint-pine (Ephedra spp.) pollen grain with a pinworm egg. This paper describes the specific Ephedra pollen morphology that can be confused with pinworm eggs.
\end{abstract}

Key words: Ephedra, Enterobius egg, palynology, pollen, pinworm, archaeology

Parasite eggs can be confused with pollen grains [1]. There are thousands of distinct pollen types [2]. Some of these types can resemble parasite eggs, and indeed, in our experience some resemble Enterobius eggs. Therefore, it is important for parasitologists working in archaeological sites to have some familiarity with palynology. This is necessary because pollen is ubiquitous and abundant in archaeological deposits [3]. In addition, pollen may be derived from dietary or medicinal species. The interdisciplinary palynology-parasitology approach to archaeological parasitology provides researchers with experience in distinguishing the morphology of parasite eggs from pollen grains.

Pinworm eggs from archaeological sites have been recovered from many sites, primarily in the Americas [4-6]. By comparing prevalence and intensity of infection from mummies and coprolites, these studies defined the New World paleoepidemiology and prehistoric biogeography of pinworm infection. Importantly, pinworm prevalence is affected by the development of complex societies and urbanization [7]. The latest re-

- Received 30 August 2019, revised 5 September 2019, accepted 5 September 2019. *Corresponding author (morganacamacho88@gmail.com) (c) 2019, Korean Society for Parasitology and Tropical Medicine This is an Open Access article distributed under the terms of the Creative Commons Attribution Non-Commercial License (http://creativecommons.org/licenses/by-nc/4.0) which permits unrestricted non-commercial use, distribution, and reproduction in any medium, provided the original work is properly cited. view of all pinworm archaeological discoveries in the Americas summarized data from 61 archaeological sites [6]. A total of 1,848 samples were analyzed for pinworm and 141 were pinworm-positive. These authors pointed out that pinworm eggs are very susceptible to decay in archaeological sites and optimal preservation was recorded only in mummies and coprolites. Pinworm eggs are rarely preserved in open site sediments. Brinkkemper and van Haaster [8] note that pinworm eggs are ephemeral and have only been found in one of dozens of European analyses. Only once have pinworm eggs been recovered from latrine sediments from the Americas [9]. The eggs have never been recovered from burial sites outside of caves. Therefore, it is important to carefully analyze pinworm egglike structures from such contexts.

Recently Paknazhad and colleagues [10] published an article in Parasites and Vectors entitled "Paleoparasitological evidence of pinworm (Enterobius vermicularis) infection in a female adolescent residing in ancient Tehran (Iran) 7,000 years ago". They based their diagnosis on a single structure illustrated in their paper. In our experience, the structure is not consistent with an oxyurid egg, but is consistent with Ephedra spp. (jointfir) pollen grain morphology. We are taking this opportunity to explain the differences between Ephedra pollen and pinworm eggs specific to this find.

Enterobius eggs have distinctive characteristics that are excep- 

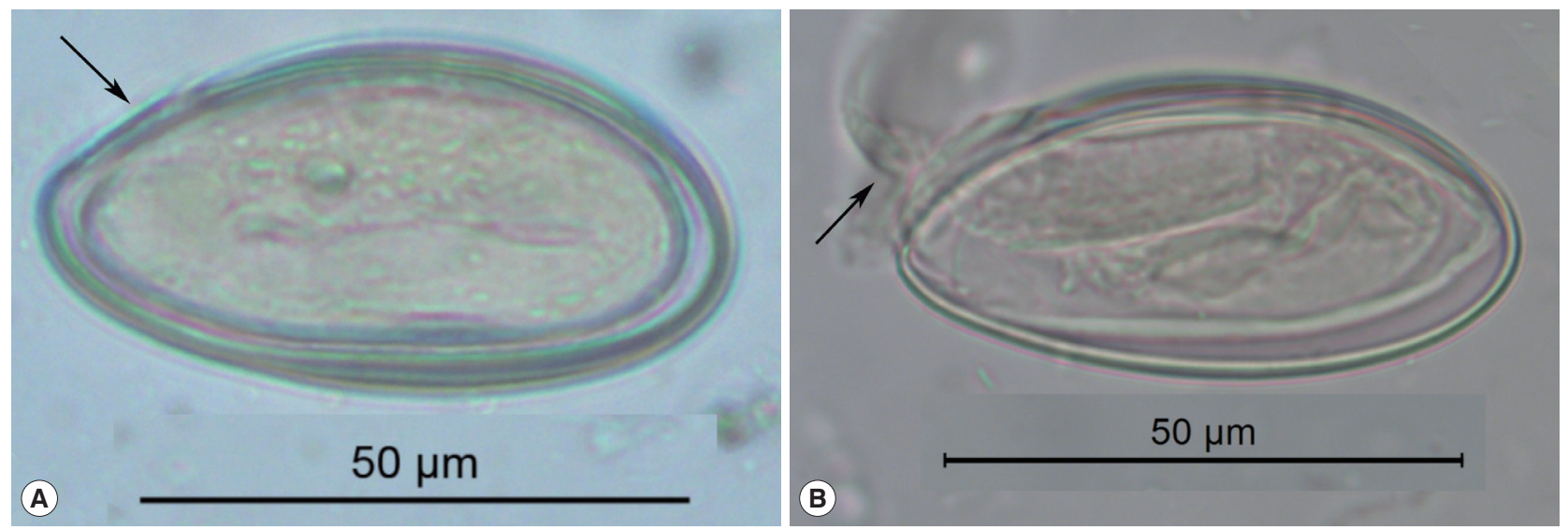

Fig. 1. These pinworm eggs were recovered from an archaeological site in Durango, Mexico and are 1,200 to 1,400 years old. In image (A), the arrow points to a thin area through which the larva exists. This point has been called operculated or capped. In image (B), a wellpreserved larva has been partly pressed out of the operculum. This image attests to the durable nature of archaeological pinworm larvae.

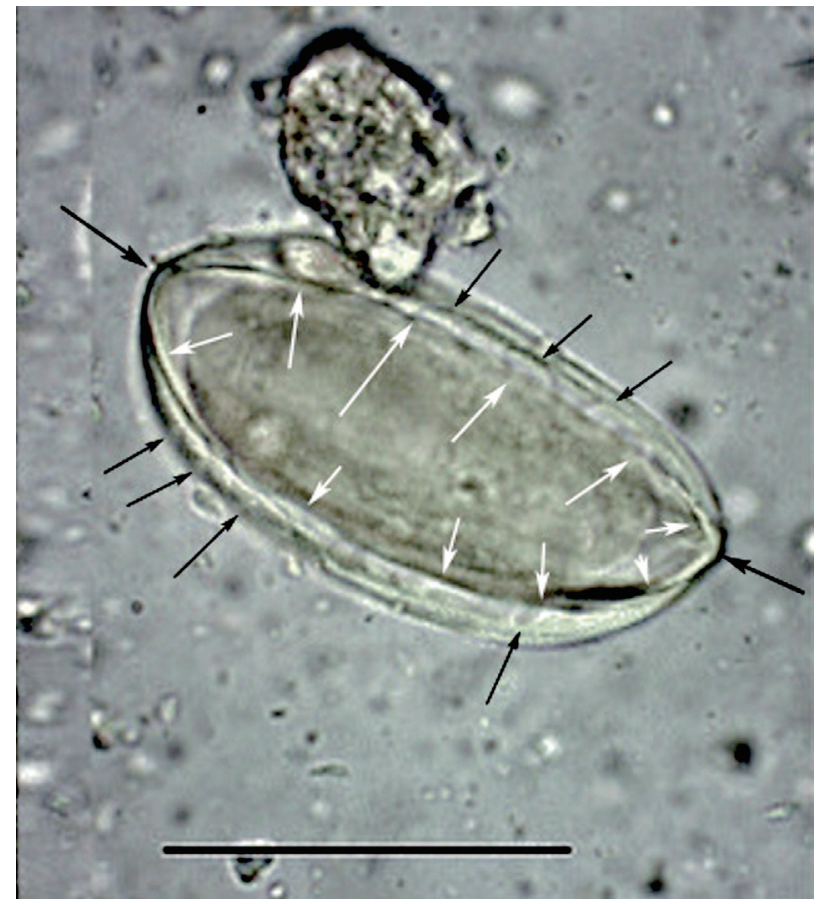

Fig. 2. This image was published by Paknazhad and colleagues [9]. The arrows point out features consistent with Ephedra pollen. The small, black arrows point laterally toward curvilinear grooves on the surface of the structure. These are called pseudosulchi and are characteristic of Ephedra pollen grains. The larger black arrows point to the ends of the object which project. This is also characteristic of Ephedra pollen. The white arrows point to visible ridges, called plicae that merge at the ends of the pollen. These are diagnostic of Ephedra. The structure is symmetrical in length and width and is thick-walled. All of these features are consistent with pollen and not Enterobius eggs.

tionally diagnostic among the helminths, and enable an accurate identification of the parasite to the species E. vermicularis.
The eggs are oval, elongate, asymmetric, slightly flattened and wider in one of the sides, making a rough "D" shape $[11,12]$. In long dimension, one end tapers more pronouncedly than the other. This taper occurs near the end where the larva exits. Some authors describe this hatching point as having an operculum or cap specifically evolved for the release of active, infective larvae from the egg [12] (Fig. 1). In our experience of analyzing thousands of ancient and modern eggs, we prefer to use the term "fissure" for application to Enterobius egg-shells (Fig. 1). This is because Enterobius spp. do not have distinct and detachable opercula like trematodes or caps like some other species of oxyurids. Enterobius vermicularis eggs are embryonated when oviposited by the female worm in the perianal area and the embryo is slightly folded inside the egg [13]. The embryos are durable in ideally preserved archaeological specimens. The egg-shell has 2 recognizable layers when visualized in light microscope and the size of the egg can vary between $50 \mu \mathrm{m}$ to $60 \mu \mathrm{m}$ in length and $20 \mu \mathrm{m}$ to $30 \mu \mathrm{m}$ in width [13] (Fig. 1). In summary, archaeological specimens are asymmetrical in lengths and cross-section, are embryonated, have a fissure, and are flattened on one side.

The object discovered by Paknazhad and her colleagues does not have any of these features [10] (Fig. 1). The object is symmetrical in length and width. It exhibits neither cap, operculum nor fissure. The characteristic flattening of one site of a pinworm egg and asymmetrical tapering of the ends are not seen. Finally, there is no embryo.

We have demonstrated that the object discovered by Paknazhad and colleagues is not consistent with a pinworm egg. Although the image of the object is blurred, there are several 


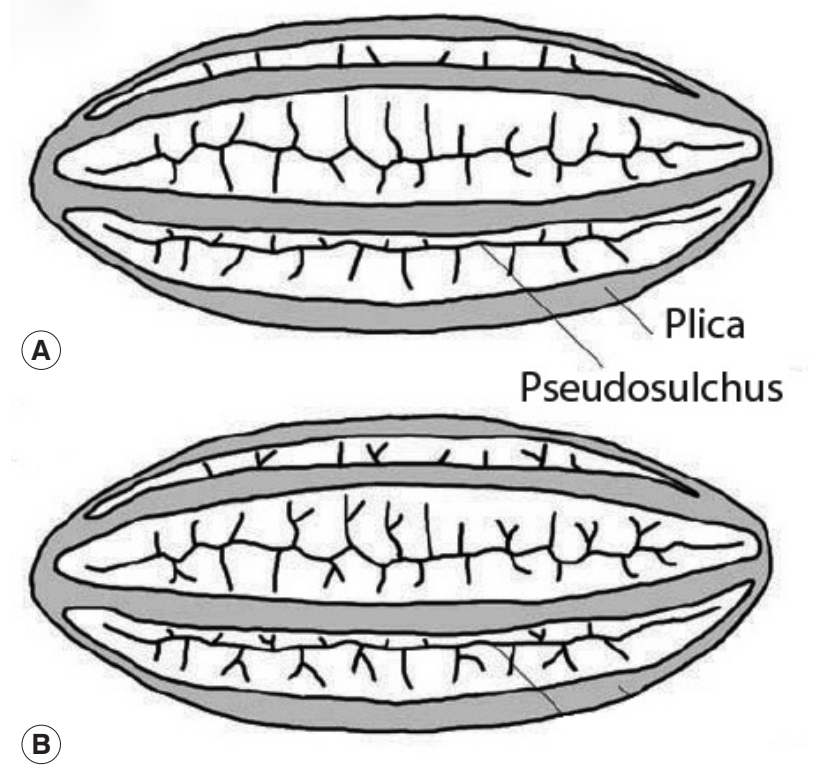

Fig. 3. This image is republished from Bolinder research group [13] who detailed the morphological changes of Ephedra pollen through the evolution of the genus from the Cretaceous Period up until now. These diagrams highlight the plicae and microsulchi that are visible in the object misdiagnosed as Enterobius by Paknazhad and colleagues [9].

noteworthy features [13] (Fig. 2). The object is symmetrical. The ends of the object are convex. The object is thick-walled. There are four ridges visible on the object. Curvilinear grooves are evident in the walls of the object. Palynologically, the ridges are called "plicae" and the grooves are called "pseudosulchi". In our opinion, it is consistent with pollen grains of Ephedra, several species of which are endemic to Iran [14]. All of these features are typical of the pollen from the genus Ephedra $[15,16]$ (Fig. 3). One common name for this genus is jointpine. Joint-pine is a genus of gymnosperm shrubs common to arid regions in the Americas, Europe, Africa and Asia. As reviewed by Bolinder and her colleagues [15], the distinct polyplicate pollen of Ephedra species varies between lineages and the arrangement of plicae and pseudosulchi can be used to trace the evolutionary origin of the genus at least to the early Cretaceous. The type found by Paknazhad and her colleagues [10] is consistent with what Bolinder and colleagues [15] described as a derived pollen type with branched pseudosulchi and fewer plicae. It is also consistent with Iran-endemic jointpine [14]. It is likely that the object is a pollen grain with six plicae, perhaps consistent with E. intermedia. Further imaging would be necessary to identify which species has been found.

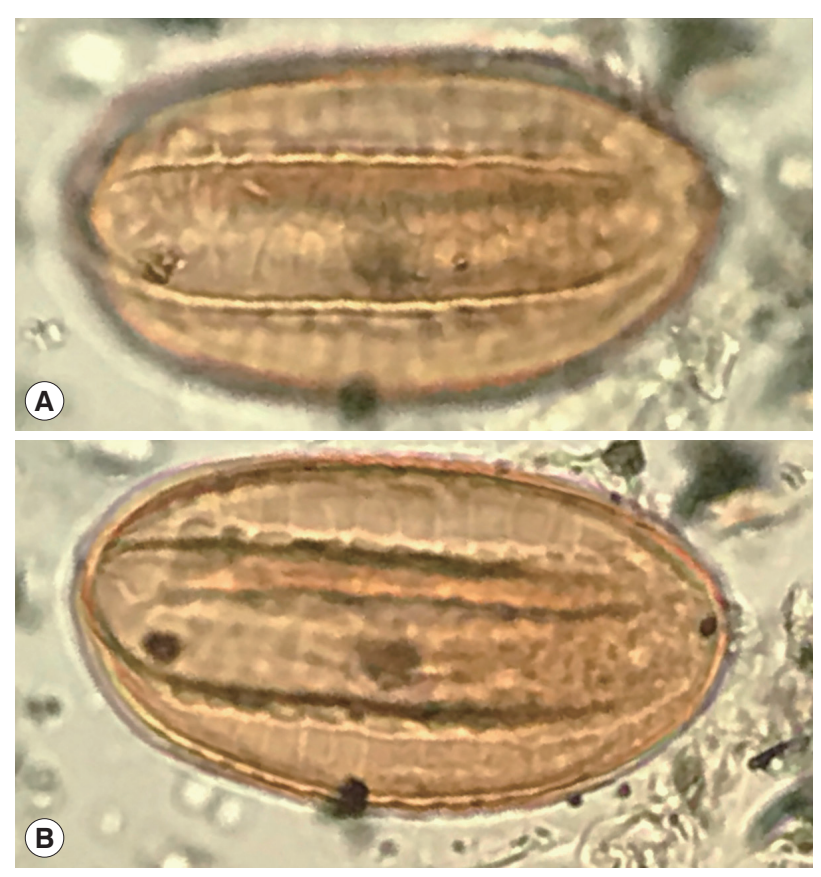

Fig. 4. A recently discovered Ephedra spp. pollen grain from an archaeological coprolite from Utah, USA that shows the characters of Ephedra pollen.

In arid regions, analyses of archaeological sites proves that pollen and macrofossils Ephedra can be encountered [16-25] (Fig. 4). Indeed, the most famous find of Ephedra pollen was in the Neanderthal burials in Shanidar Cave, Iraq $[19,20,24]$. Joint-fir was economically important, but is also an ambient, wind-dispersed type. Therefore, it is a common contaminant. Ephedra pollen has long been found as a common background type in archaeological and modern pollen studies in Iran $[26,27]$. The object found by Paknazhad and her colleagues matches closely the general shape Ephedra pollen recovered from burial soils in China with the exception that the Chinese example is of a species that does not have pseudosulchi [16]. Ephedra pollen is commonly found in archaeological sites and represents environmental conditions in low quantities $[16,28-$ 30] or medicinal use if found in high concentrations [23]. The Shanidar find has been interpreted as representing early human recognition of the medicinal value of the species [20].

Based on the morphology of the object reported by Paknazhad and colleagues, it appears that they made an error in confusing this pollen grain with a parasite egg. The importance of the knowledge of pollen shapes cannot be overstated when examining sediments from archaeological sites, since many 
morphometries can be misunderstood as parasite eggs. In this case, distinct features of polyplicate pollen are evident. We recommend the reestablishment of the multidisciplinary approach to research pioneered by Anderson (parasitologist) and Hevly (palynologist) in order to aid parasitological research in archaeological sediments [9].

\section{CONFLICT OF INTEREST}

The authors declare no conflict of interest related to this study.

\section{REFERENCES}

1. John DT, Petri W. Markell and Voge's Medical Parasitology. 9th ed. Missouri, USA. Saunders Elsevier. 2006, pp 480.

2. Traverse A. Paleopalynology. 2nd ed. Dordrecht, Netherlands. Springer. 2007, pp 1-813.

3. Deforce K, Van Hove M, Willems D. Analysis of pollen and intestinal parasite eggs from medieval graves from Nivelles, Belgium: taphonomy of the burial ritual. J Archaeol Sci Rep 2015; 4: 596-604.

4. Camacho M, Reinhard KJ. Pinworm research in the Southwest USA: five decades of methodological and theoretical development and the epidemiological approach. Archaeol Anthrop Sci (in press).

5. Morrow JJ, Reinhard KJ. The paleoepidemiology of Enterobius vermicularis (Nemata: Oxyuridae) among the Loma San Gabriel at La Cueva de los Muertos Chiquitos (600-800 CE), Rio Zape Valley, Durango, Mexico. Comp Parasitol 2018; 85: 27-33.

6. Reinhard K, Araújo A, Morrow J. Temporal and spatial distribution of Enterobius vermicularis (Nemata: Oxyuridae) in the prehistoric Americas. Korean J Parasitol 2016; 54: 591-603.

7. Reinhard KJ. Cultural ecology of prehistoric parasitism on the Colorado Plateau as evidenced by coprology. Am J Phys Anthropol 1988; 77: 355-366.

8. Brinkkemper O, van Haaster H. Eggs of intestinal parasites whipworm (Trichuris) and mawworm (Ascaris): non-pollen palynomorphs in archaeological samples. Rev Palaeobot Palyno 2012; 186: 16-21.

9. Hevly R, Kelly R, Anderson G, Olsen S. Comparative effects of climate change, cultural impact, and volcanism in the paleoecology of Flagstaff, Arizona, A.D. 900-1300. In Sheets PD, Grayson DK eds, Volcanic Activity and Human Ecology. New York, USA. Academic Press. 1979, pp 487-523.

10. Paknazhad N, Mowlavi G, Camet JD, Jelodar ME, Mobedi I, Makki M, Kia EB, Rezaeian M, Mohebali M, Sarlak S, Najafi F. Paleoparasitological evidence of pinworm (Enterobius vermicularis) infection in a female adolescent residing in ancient Tehran (Iran) 7000 years ago. Parasit Vectors 2016; 9: 33.
11. Hugot JP, Gardner SL, Borba V, Araujo P, Leles D, Stock Da-Rosa ÁA, Dutra J, Ferreira LF, Araújo A. Discovery of a 240 million year old nematode parasite egg in a cynodont coprolite sheds light on the early origin of pinworms in vertebrates. Parasit Vectors 2014; 7: 486.

12. Hugot JP, Tourte-Schaefer C. Étude morphologique des deux Oxyures parasites de l'homme: Enterobius vermicularis et E. gregorii. Ann Parasitol Hum Comp 1985; 60: 57-64.

13. Roberts LS, Janovy Jr J, Nadler S. Nematodes: Oxyuridomorpha, Pinworms. In Roberts LS, Janovy Jr J, Nadler S eds, Gerald D Schmidt \& Larry S Roberts' Foundations of Parasitology. 9th ed. New York, USA. McGraw-Hill International. 2013, pp 425-430.

14. Akhtar T, Ershadi M, Azizian D, Asadi M. A study on pollen morphology of the genus Ephedra L. in Iran. Iran J Biol 2004; 17: 49-58.

15. Bolinder K, Ivarsson LN, Humphreys AM, Ickert-Bond SM, Han F, Hoorn C, Rydin C. Pollen morphology of Ephedra (Gnetales) and its evolutionary implications. Grana 2016; 55: 24-51.

16. Li JF, Abuduresule I, Hueber FM, Li WY, Hu XJ, Li YZ, Li CS. Buried in sands: environmental analysis at the archaeological site of Xiaohe Cemetery, Xinjiang, China. PLoS One 2013; 8: e68957.

17. Dominguez S, Reinhard KJ, Sandness KL, Edwards CA, Danielson D. The Dan Canyon Burial, 42A21339, a P III burial in Glen Canyon National Recreation Area. Nebraska, USA. Midwest Archeological Center Occasional Studies No. 26. 1992, pp 108.

18. Hamilton DL, Bratten JR. The Rustler Hills Economic Pollen Spectrum. In Hamilton DL ed, Prehistory of the Rustler Hills: Granado Cave. Texas, USA. University of Texas Press. 2001, pp 240-250.

19. Leroi-Gourhan A. Shanidar et ses fleurs. Paléorient 1998, 24: 7988 (in French).

20. Lietava J. Medicinal plants in a Middle Paleolithic grave Shanidar IV? J Ethnopharmacol 1992; 35: 263-266.

21. Mair VH. The mummies of East Central Asia. Expedition 2010; 52: 23-32.

22. Reinhard KJ, Geib PR, Callahan MM, Hevly RH. Discovery of colon contents in a skeletonized burial: soil sampling for dietary remains. J Archaeol Sci 1992; 19: 697-705.

23. Reinhard K, Hammilton D, Hevly R. Use of pollen concentration in paleopharmacology: coprolite evidence of medicinal plants. J Ethnobiol 1991; 11: 117-132.

24. Solecki RS. Shanidar IV, a Neanderthal flower burial in Northern Iraq. Science 1975; 190: 880-881.

25. Zhang G, Wang S, Ferguson DK, Yang Y, Liu X, Jiang H. Ancient plant use and palaeoenvironmental analysis at the Gumugou Cemetery, Xinjiang, China: implication from desiccated plant remains. Archaeol Anthrop Sci 2017; 9: 145-152.

26. Djamali M, de Beaulieu JL, Andrieu-Ponel V, Berberian M, Miller NF, Gandouin E, Lahijani H, Shah-Hosseini M, Ponel P, Salimian M, Guiter F. A late Holocene pollen record from Lake Almalou in NW Iran: evidence for changing land-use in relation to some historical events during the last 3700 years. J Archaeol Sci 2009; 36: 1364-1375. 
27. van Zeist W, Bottema S. Palynological investigations in Western Iran. Palaeohistoria 1977; 19: 19-85.

28. Reinhard KJ, Edwards S, Damon TR, Meier DK. Pollen concentration analysis of Ancestral Pueblo dietary variation. Palaeogeogr Palaeoclimatol Palaeoecol 2006; 237: 92-109.

29. Reinhard KJ, Johnson KL, LeRoy-Toren S, Wieseman K, TeixeiraSantos I, Vieira M. Understanding the pathoecological relation- ship between ancient diet and modern diabetes through coprolite analysis: a case example from Antelope Cave, Mojave County, Arizona. Curr Anthropol 2012; 53: 506-512.

30. Xu D, Lu H, Chu G, Wu N, Shen C, Wang C, Mao L. 500-year climate cycles stacking of recent centennial warming documented in an East Asian pollen record. Sci Rep 2014; 4: 3611. 
